\title{
ESSAY \\ Strengthening Pandemic Preparedness Through Noncommunicable Disease Strategies
}

\author{
Deliana A. Kostova, $\mathrm{PhD}^{1}$; Ronald L. Moolenaar, $\mathrm{MD}^{1}$; Gretchen Van Vliet, $\mathrm{MPH}^{2}$; \\ Ally Lasu, $\mathrm{MPH}^{2}$; Michael Mahar, $\mathrm{PhD}^{1}$; Patricia Richter, $\mathrm{PhD}^{1}$
}

Accessible Version: www.cdc.gov/pcd/issues/2021/21_0237.htm

Suggested citation for this article: Kostova DA, Moolenaar RL, Van Vliet G, Lasu A, Mahar M, Richter P. Strengthening Pandemic Preparedness Through Noncommunicable Disease Strategies. Prev Chronic Dis 2021;18:210237. DOI: https:// doi.org/10.5888/pcd18.210237.

\section{PEER REVIEWED}

The COVID-19 pandemic has demonstrated the effect of noncommunicable diseases (NCDs) on infectious disease outcomes. This effect can be observed at both the individual and the population level. At the individual level, the presence of preexisting chronic conditions increases a patient's risk of severe COVID-19 disease (1). At the population level, the aggregate prevalence of chronic conditions could compound the pandemic's overall burden on health systems and the economy (2).

Given the role of NCDs in infectious disease and pandemic outcomes, future pandemic preparedness plans could be improved by incorporating selected NCD-related objectives to complement the plans' core focus on infectious diseases. In a previous publication, we presented a conceptual framework that outlined the points of convergence among infectious disease outbreaks, pandemic preparedness, and NCDs (3). We ascertained that NCDs play a role in 4 factors that determine the course of infectious disease outbreaks: the host population, the disease agent, the physical environment, and the social environment. First, the increased prevalence of NCDs in a host population raises its susceptibility to outbreaks, while also playing into a reverse feedback loop where infection in an individual patient can independently generate NCD sequelae, requiring treatment of both. Second, the presence of NCDs and their risk factors can exacerbate the pathogenicity of the infectious disease agent. Third, the prevalence of NCDs shapes the physical environment by steering health systems toward primary care, where the resulting infrastructure can support pandemic response by increasing staffing and supplementing supply chains. Fourth, the prevalence of NCDs affects the social environment by driving health care budgets and providing avenues for sustainable financing. In summary, the multipronged role of NCDs in infectious disease outbreaks merits their consideration in pandemic strategy building.

The International Health Regulations (IHR) (4) constitute a global agreement among 196 signatory countries that represents the world's coordinated effort to prepare for and limit the spread of epidemics. Established in 2005 under the auspices of the World Health Organization, IHR delineates a set of approaches that participating countries can use to strengthen key pandemic capacities, including capacities for surveillance, risk communications, human resources, laboratory testing, national legislation, coordination, response, and operational readiness (5). In 2014, multiple countries partnered to accelerate compliance with the 2005 IHR by developing the Global Health Security Agenda (GSHA) (6). However, despite the demonstrable relevance of NCDs to pandemic outcomes, neither IHR nor GHSA preparedness plans refer to NCDrelated aspects of public health protection, potentially overlooking an important ingredient in global health security.

We posit that international pandemic prevention strategies, such as IHR and GHSA, can be improved by incorporating key NCDrelated components. We identify 6 action areas in IHR and GHSA that are appropriate for integrating NCD-related objectives: surveillance, workforce development, laboratory systems, immunization, risk communication, and sustainable financing (3).

Surveillance. Surveillance, or the collection of population health data, is a core component of disease prevention and control. Including NCD-related data in GHSA surveillance initiatives provides several advantages to health security. First, it can support the development of population risk profiles, which can inform resource mobilization and health system planning (7-9). Second, it can improve the detection of the sequelae of infectious diseases, for example, HIV-associated NCD complications $(10,11)$. Third, by signaling responsiveness and a long-term commitment to local health needs that is not limited to emergency 
events, it can broaden local support of GHSA/IHR priorities $(12,13)$.

Workforce development. Workforce development refers to strengthening the skills of clinicians and other health professionals in supporting national public health priorities. Mechanisms for workforce development include initiatives such as the Field Epidemiology Training Program (14) and programs for training community health workers. The Field Epidemiology Training Program traditionally focuses on developing expertise in infectious disease epidemiology, but it can be adjusted to incorporate NCDrelated curricula as well (15-17). Likewise, training programs for community health workers in countries whose populations have limited access to health care are well positioned to develop frontline workers who can bridge gaps in basic care between common NCD conditions and infectious disease prevention and control $(18-20)$.

Laboratory systems. IHR and GHSA both emphasize the importance of establishing essential laboratory capacity in participating countries (21). Besides requiring assays for detection of pathogens commonly linked to epidemic diseases such as influenza, polio, HIV, tuberculosis, malaria, and salmonella, GHSA laboratory initiatives can allow for analysis of biomarkers of key NCD conditions. This capacity may facilitate whole-patient care while increasing economies of scale in laboratory processing.

Immunization. Vaccination against infectious pathogens that raise the risk of NCDs presents a unique opportunity for integrating global health security and NCD-related objectives. Vaccines for NCD risk reduction include, for example, those that protect against infection with human papillomavirus (a risk factor for cervical cancer) and hepatitis B (a risk factor for liver disease). Besides strengthening population health, vaccinations that reduce the risk of NCDs can support IHR and GHSA objectives by establishing vaccination channels among adults (22).

Risk communication. Risk communication is a valuable element of pandemic control (23). Including NCD-related information in emergency risk communication plans can improve response to infectious outbreaks in populations with comorbid conditions that make them vulnerable to infection.

Sustainable financing. Communicable and noncommunicable diseases increasingly depend on a shared health infrastructure $(24,25)$. Shared infrastructure elements such as procurement channels can increase cost and operational efficiency. For example, the Pan American Health Organization Strategic Fund, a mechanism for procuring essential health supplies in the Pan American region, aggregates the supply of medications across the disease spectrum, increasing overall financial sustainability through economies of scale (26). Furthermore, NCD prevention approaches such as tobacco and alcohol taxation can be used to bolster the financial sustainability of health systems in low-income and middle-income countries (27-29).

The COVID-19 pandemic has amplified the importance of NCDs to outbreak preparedness and response. It has highlighted challenges experienced by health care systems worldwide in containing a severe infectious disease outbreak intensified by concurrent chronic health conditions. The aggravating effect of NCD comorbidities that disproportionately affect socioeconomically vulnerable groups has deepened equity concerns. Responding to the compounding burden of NCDs may improve readiness for public health emergencies.

\section{Acknowledgments}

The findings and conclusions in this report are those of the authors and do not necessarily represents the official position of the Centers for Disease Control and Prevention. No copyrighted materials were used in this article.

\section{Author Information}

Corresponding Author: Deliana A. Kostova, PhD, Division of Global Health Protection, Centers for Disease Control and Prevention, 1600 Clifton Rd, Atlanta, GA 30322. Telephone: 404747-8978. Email: kiv0@cdc.gov.

Author Affiliations: ${ }^{1}$ Division of Global Health Protection, Centers for Disease Control and Prevention, 1600 Clifton Rd, Atlanta, Georgia. ${ }^{2}$ RTI International, Research Triangle Park, North Carolina.

\section{References}

1. Centers for Disease Control and Prevention. Science brief: underlying medical conditions associated with high risk for severe COVID-19: information for healthcare providers. 2021. https:/www.cdc.gov/coronavirus/2019-ncov/hcp/clinical-care/ underlyingconditions.html. Accessed June 1, 2021.

2. Clark A, Jit M, Warren-Gash C, Guthrie B, Wang HHX, Mercer SW, et al.; Centre for the Mathematical Modelling of Infectious Diseases COVID-19 Working Group. Global, regional, and national estimates of the population at increased risk of severe COVID-19 due to underlying health conditions in 2020: a modelling study. Lancet Glob Health 2020; 8(8):e1003-17.

The opinions expressed by authors contributing to this journal do not necessarily reflect the opinions of the U.S. Department of Health and Human Services, the Public Health Service, the Centers for Disease Control and Prevention, or the authors' affiliated institutions. 
3. Kostova D, Richter P, Van Vliet G, Mahar M, Moolenaar RL. The role of noncommunicable diseases in the pursuit of global health security. Health Secur 2021;19(3):288-301.

4. World Health Organization. International Health Regulations. 2005. https://www.who.int/ihr/about/en. Accessed May 1, 2021.

5. World Health Organization. IHR core capacity monitoring framework: checklist and indicators for monitoring progress in the development of IHR core capacities in states parties. 2013. https://apps.who.int/iris/bitstream/handle/10665/84933/WHO HSE_GCR_2013.2_eng.pdf?sequence=1. Accessed May 1, 2021.

6. Global Health Security Agenda. The 6th GHSA Ministerial Meeting. https://ghsagenda.org. Accessed May 1, 2021.

7. Day C, Groenewald P, Laubscher R, Chaudhry S, Van Schaik $\mathrm{N}$, Bradshaw D. Monitoring of non-communicable diseases such as hypertension in South Africa: challenges for the post2015 global development agenda. S Afr Med J 2014; 104(10):680-7.

8. Gouda HN, Richards NC, Beaglehole R, Bonita R, Lopez AD. Health information priorities for more effective implementation and monitoring of non-communicable disease programs in low- and middle-income countries: lessons from the Pacific. BMC Med 2015;13(1):233.

9. Accorsi S, Kedir N, Farese P, Dhaba S, Racalbuto V, Seifu A, et al. Poverty, inequality and health: the challenge of the double burden of disease in a non-profit hospital in rural Ethiopia. Trans R Soc Trop Med Hyg 2009;103(5):461-8.

10. Lorenzoni C, Oliveras L, Vilajeliu A, Carrilho C, Ismail MR, Castillo $\mathrm{P}$, et al. Weak surveillance and policy attention to cancer in global health: the example of Mozambique. BMJ Glob Health 2018;3(2):e000654.

11. Wilson HW, Amo-Addae M, Kenu E, Ilesanmi OS, Ameme DK, Sackey SO. Post-Ebola syndrome among Ebola virus disease survivors in Montserrado County, Liberia 2016. BioMed Res Int 2018;2018:1909410-8.

12. Kostova D, Husain MJ, Sugerman D, Hong Y, Saraiya M, Keltz J, et al. Synergies between communicable and noncommunicable disease programs to enhance global health security. Emerg Infect Dis 2017;23(13):S40-6.

13. Hanefeld J, Mayhew S, Legido-Quigley H, Martineau F, Karanikolos M, Blanchet K, et al. Towards an understanding of resilience: responding to health systems shocks. Health Policy Plan 2018;33(3):355-67.

14. Centers for Disease Control and Prevention. Global health protection and security. About FETP. https://www.cdc.gov/ globalhealth/healthprotection/fetp/about.html. Accessed May $1,2021$.
15. Ario AR, Bulage L, Kadobera D, Kwesiga B, Kabwama SN, Tusiime P, et al. Uganda public health fellowship program's contribution to building a resilient and sustainable public health system in Uganda. Glob Health Action 2019; 12(1):1609825-1609825.

16. Senkomago V, Duran D, Loharikar A, Hyde TB, Markowitz LE, Unger ER, et al. CDC activities for improving implementation of human papillomavirus vaccination, cervical cancer screening, and surveillance worldwide. Emerg Infect Dis 2017;23(13):S101-7.

17. Subramanian RE, Herrera DG, Kelly PM. An evaluation of the global network of field epidemiology and laboratory training programmes: a resource for improving public health capacity and increasing the number of public health professionals worldwide. Hum Resour Health 2013;11(1):45-45.

18. Kruk ME, Nigenda G, Knaul FM. Redesigning primary care to tackle the global epidemic of noncommunicable disease. Am J Public Health 2015;105(3):431-7.

19. Abrahams-Gessel S, Denman CA, Montano CM, Gaziano TA, Levitt N, Rivera-Andrade A, et al. Training and supervision of community health workers conducting population-based, noninvasive screening for CVD in LMIC: implications for scaling up. Glob Heart 2015;10(1):39-44.

20. Joshi R, Thrift AG, Smith C, Praveen D, Vedanthan R, Gyamfi J, et al. Task-shifting for cardiovascular risk factor management: lessons from the Global Alliance for Chronic Diseases. BMJ Glob Health 2018;3(Suppl 3):e001092.

21. World Health Organization. Joint external evaluation tool: International Health Regulations (2005). 2016. https:// apps.who.int/iris/bitstream/handle/10665/204368/ 9789241510172 e n g.pdf; j s e s s i o n i d= 6357F4B5A8B4D9FE33955EEFFD33EE5C? sequence $=1$. Accessed May 1, 2021.

22. Senkomago V, Duran D, Loharikar A, Hyde TB, Markowitz LE, Unger ER, et al. CDC activities for improving implementation of human papillomavirus vaccination, cervical cancer screening, and surveillance worldwide. Emerg Infect Dis 2017;23(13):S101-7.

23. World Health Organization. Emergencies: risk communication. https://www.who.int/news-room/q-a-detail/emergencies-riskcommunication. Accessed May 1, 2021.

24. Siddharthan T, Ramaiya K, Yonga G, Mutungi GN, Rabin TL, List JM, et al. Noncommunicable diseases in East Africa: assessing the gaps in care and identifying opportunities for improvement. Health Aff (Millwood) 2015;34(9):1506-13.

25. Jakovljevic M, Jakab M, Gerdtham U, McDaid D, Ogura S, Varavikova E, et al. Comparative financing analysis and political economy of noncommunicable diseases. J Med Econ 2019;22(8):722-7.

The opinions expressed by authors contributing to this journal do not necessarily reflect the opinions of the U.S. Department of Health and Human Services, the Public Health Service, the Centers for Disease Control and Prevention, or the authors' affiliated institutions. 
26. Pan American Health Organization. 2017. Recommendations of the Expert Committee for the Selection and Inclusion of Medicines in the PAHO's Strategic Fund 2015. http:// iris.paho.org/xmlui/handle/123456789/28205. Accessed May $1,2021$.

27. Charoenca N, Kungskulniti N, Mock J, Hamann S, Vathesatogkit P. How Thailand's greater convergence created sustainable funding for emerging health priorities caused by globalization. Glob Health Action 2015;8(1):28630.

28. Watkins DA, Yamey G, Schäferhoff M, Adeyi O, Alleyne G, Alwan A, et al. Alma-Ata at 40 years: reflections from the Lancet Commission on Investing in Health. Lancet 2018; 392(10156):1434-60.

29. Ottersen T, Elovainio R, Evans DB, McCoy D, Mcintyre D, Meheus F, et al. Towards a coherent global framework for health financing: recommendations and recent developments. Health Econ Policy Law 2017;12(2):285-96. 